\title{
Hôtel-Dieu de París; reformas materiales, estructurales y funcionales entre los siglos XII y XVIII
}

\section{Hôtel-Dieu in Paris; material, structural and functional reforms, between twelve and eighteenth centuries}

\section{Hôtel-Dieu em Paris; reformas materiais, estruturais e funcionais entre os séculos XII e XVIII}

Teresa Morales, Cristina ${ }^{1}$; García Berrocal, Francisco Javier ${ }^{2}$

${ }^{1 y 2}$ Diplomada/o universitaria en enfermería.

Cómo citar este artículo en edición digital: Teresa Morales, C. y Garcia Berrocal, FJ. (2013) Hôtel-Dieu de París; reformas materiales, estructurales y funcionales entre los siglos XII y XVIII. Cultura de los Cuidados (Edición digital) 17, 36. Disponible en: http://dx.doi.org/10.7184/cuid.2013.36.04

Correspondencia: Cristina Teresa Morales; Avd. San Antonio n5, 1º ; 21004 Huelva. Tf.959222127.

Correo electrónico: cristina.teresa.morales@gmail.com

Recibido 3/03/2013. Aceptado 07/05/2013.

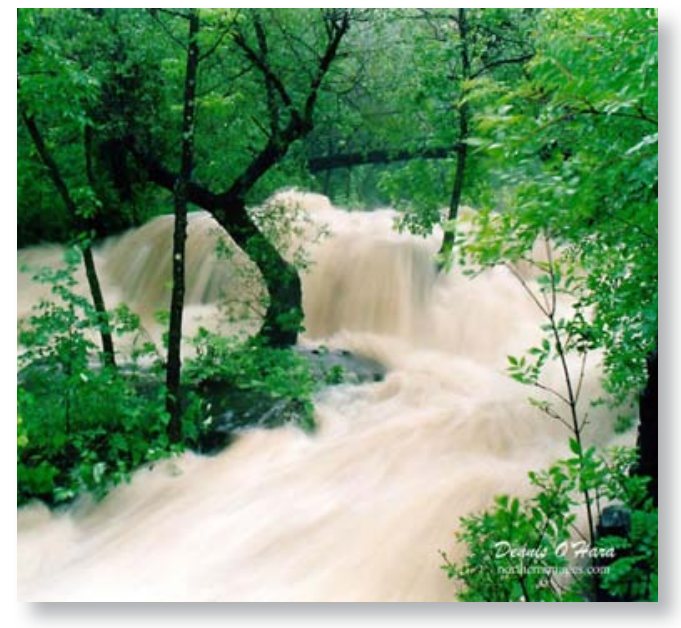

ABSTRACT

The objective of the present study is discover and disclose the history of the Hôtel-Dieu in Paris between twelve and eighteenth centuries, period of time when some big facilities where built the administration system was changed and an Agustinian Sisters functional structure was developed with the implementation of supervisors and some specialist in different areas. The methodology used in this study is cualitative-descriptive that begins with the bibliography research and followed by an hermeneutic analysis of the documents that were found. The conclusions of this revision relate to the issue of the difficulties faced in order to change from and caritative-religious management of the sanitary assistance to a laic management, loosing in this process it altruistic conception; the development of this high-scale facility for sanitary attention and also the administration, both hierarchy and functional. All this during a wide six centuries

Keywords: Hôtel-Dieu in Paris; Agustinian Sisters Hospital; Medieval Hospital; Nursing Care in the Middle Age.

\section{RESUMO}

O presente estudo tem como objetivo conhecer e divulgar a história do HôtelDieu de Paris entre os séculos XII e XVIII, período de tempo no qual se levaram a cabo grandes obras em suas instalações, se mudou o sistema de administração e se desenvolveu uma estrutura funcional das Irmãs Agostinianas com o aparecimento de supervisoras e especialistas em diferentes áreas. A metodologia usada para este estudo 
é a de investigação qualitativo-descritiva que se inicia com uma pesquisa bibliográfica e se continua com a análise hermenêutica dos documentos encontrados. As conclusões deste estudo versam sobre a problemática do passo da gestão da assistência sanitária caritativoreligiosa à gestão laica da mesma com a perda do cariz altruísta; do desenvolvimento de superestruturas físicas para a atenção sanitária e das hierarquias organizativas e funcionais dessas superestruturas, tudo isto em um amplo contexto temporário de seis séculos.

Palavras-chave: Hôtel-Dieu em Paris; Hospital Irmãs Agostinianas; Hospitais Medievais; Cuidados de Enfermagem na Idade Média.

\section{RESUMEN}

El presente estudio tiene como objetivo conocer y divulgar la historia del Hôtel-Dieu de París entre los siglos XII y XVIII, periodo de tiempo en el que se llevaron a cabo grandes obras en sus instalaciones, se cambió el sistema de administración y se desarrolló una estructura funcional de las Hermanas Agustinas con la aparición de supervisoras y especialistas en diferentes áreas. La metodología usada para este estudio es de investigación cualitativo-descriptiva que se inicia con una búsqueda bibliográfica y continúa con el análisis hermenéutico de los documentos encontrados. Las conclusiones de este estudio versan sobre la problemática del paso de la gestión de la asistencia sanitaria caritativo-religiosa a la gestión laica de la misma con la pérdida del cariz altruista; del desarrollo de súper-estructuras físicas para la atención sanitaria y de las jerarquías organizativas y funcionales de esas súper-estructuras, todo esto en el amplio contexto temporal de seis siglos.
Palabras clave: Hôtel-Dieu de París; Hermanas Agustinas Hospitalarias; Hospitales Medievales; Cuidados Enfermeros en la Edad Media.

\section{INTRODUCCIÓN}

Los servicios públicos de asistencia sociosanitaria de la ciudad de París fueron gestionados, durante muchos siglos, por la Iglesia Católica a través de la Sede Episcopal de dicha villa (Coyecque, 1891), al igual que ocurría en la mayoría de las ciudades europeas durante la Edad Media. Desde los siglos VII hasta el XIII, esta asistencia se prestó en un pequeño hospital, el Hospital de San Cristóbal, ubicado junto a una capilla dedicada al mismo santo, cuyos orígenes ya se pormenorizaron en nuestro estudio previo: "Hôtel-Dieu de París: orígenes y aparición de las primeras enfermeras religiosas de la historia" (Teresa, 2013).

En este hospital episcopal, prestaron sus servicios las Hermanas de San Cristóbal (Mackay, 1923), un pequeño grupo de mujeres que, en un principio, se dedicaban al cuidado de la capilla, al blanqueamiento de las ropas y a la atención de los capellanes (Nutting, 1907) pero que, aproximadamente por el siglo VIII, comienzan a atender a los enfermos del hospital por orden del obispo (Aparicio, 1979). Fueron una congregación secular hasta 1217 , fecha en la se establece el primer estatuto de los hermanos y hermanas del hospital (Dubois, 1710) y pasan a ser orden regular, acogidas a la Regla de San Agustín, por lo que cambian su denominación a "Hermanas Agustinas". Por la misma época se cambia también el nombre del hospital, denominándose Hôtel-Dieu, por lo que la congregación pasa a ser conocida popularmente como "Hermanas Agustinas del Hôtel-Dieu” (Mackay, 1923). 
El desarrollo comercial dado en la Baja Edad Media provoca el rápido crecimiento y la emancipación de las ciudades, lo que genera el aumento de población en las mismas (Siles, 2011) y, por lo tanto, también aumenta el número de enfermos, pobres, huérfanos y desprotegidos en general. Esta misma realidad es la que se vive en el París del siglo XII, lo que produce que aquellas primitivas instalaciones junto a la capilla de San Cristóbal sean insuficientes para la demanda asistencial que recibían y exige un aumento de personal (Coyecque, 1891) y de los conocimientos y técnicas que éstos debían poseer. Todo esto hace que nos encontremos, en el s. XIII, con una amplia renovación del Hôtel-Dieu; en lo material, vamos a ver una cambio en la ubicación y una ambiciosa construcción, así como un gran número de reformas y ampliaciones posteriores; en lo estructural, vamos a descubrir cómo va a cambiar su jerarquía interna, tomando cada vez más control el gobierno laico frente al religioso; y en el plano funcional vamos a asistir a la entrada de los médicos y cirujanos al hospital, a la desaparición de los hermanos, al germen de la profesionalización y especialización de las hermanas enfermeras en las diferentes salas y a la aparición de las "supervisoras" de sala.

\section{ESTADO DE LA CUESTIÓN}

En la amplia búsqueda bibliográfica realizada en las diferentes bases de datos, hemos encontrado diferentes artículos científicos, libros, manuales, artículos de prensa...que nos han ayudado en la elaboración de este estudio. En publicaciones de revistas podemos reseñar los siguientes; Castro Molina, F.C. (2012), Álvaro Barra, M.P. (2001), Monje Juárez, M. (1998, 2003), Ferrer Cano, F. (2001), Parrilla Saldaña, J. (1999), Eseverri Chaverri, C. (1996-
1997), García Oro, J. (2001), Aliete Pedrosa (2003), Aparicio (1979), Jehanno, C. (1986), Cheymol, J. (1977), Valentin, M. (1977), Pietra Santa, de P. (1866), Gazette Medicale (1838), Boudon, G. (1903), Gannal, F. (1892) y Coyecque, E. (1988). También acudimos a los siguientes volúmenes: de historia de la enfermería podemos destacar, Nutting, A. (1901), Donahue, M.P. (1985) y Siles González, J. (1999); sobre la historia de París y su relación con la Iglesia Católica: Dubois (1710), Filibien, M. (1725), Mackay, M.L. (1923) y Lebeuf, J. (1754) y sobre la historia específica del HôtelDieu de París; Coyecque, E. (1891), Briele, L. (1870) y Chevalier, A. (1901).

La documentación encontrada nos ha servido para conocer el contexto político, religioso, social y cultural de este estudio, para descubrir los cambios físicos, estructurales y funcionales que acontecieron en el Hôtel-Dieu de París desde el s. XII al XVIII y la labor asistencial de las Hermanas Agustinas durante este vasto periodo de tiempo.

\section{MÉTODOS}

La presente investigación se podría definir como de tipo cualitativo descriptivo longitudinal y se ha llevado a cabo en tres fases. Una primera de búsqueda bibliográfica, en la que se utilizaron las siguientes bases de datos: Cuiden, Cochrane Plus, Dialnet, Francofil, Pascal, Refdoc, Biusante, Gallica y Europeana, también hemos usado los Catálogos Generales de la Universidad de Huelva, Extremadura y Biblioteca Digital Cecova. Para esta búsqueda se usaron los descriptores: Hôtel-Dieu/ Hôtel-Dieu de París/ Hermanas Agustinas/ hospitales; medievales, en la Edad Media, en el Renacimiento, católicos, católicos en Francia/ cuidados de enfermería; medieval, en la Edad Media, en el Renacimiento, hospitalarios en 


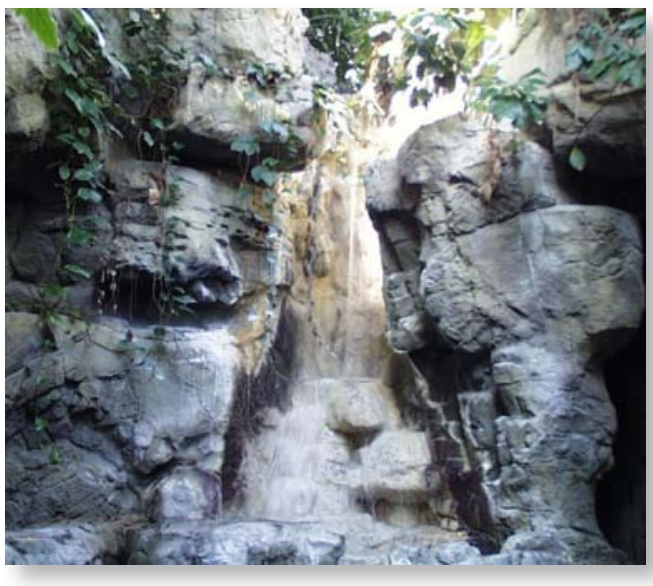

el Renacimiento/ enfermería; medieval, en la Edad Media, en el Renacimiento, hospitalaria en el Renacimiento/ monjas enfermeras/ religiosas enfermeras/ caridad y hospitales/ religión y enfermería.

Después abordamos una segunda etapa de revisión de la documentación reseñada, en la que se descartaron o incluyeron aquellos documentos que se adaptaban a nuestros objetivos, contenidos, temporalidad... previa traducción de la mayoría de los documentos, por lo que debemos hacer hincapié en que las traducciones usadas han sido realizadas por los autores. Posteriormente, se lleva a cabo la fase de análisis hermenéutico en el que se produce la lectura en profundidad, comparativa entre autores, análisis crítico, y reflexión de todos los documentos mencionados. El resultado de todo este proceso es el presente trabajo, en el que se van a desentrañar los aspectos más importantes de la historia del Hôtel-Dieu de París, desde el siglo XII hasta el XVIII, concretamente hasta 1772, año en el que el hospital quedó muy dañado por un gran incendio.

\section{MARCO HISTÓRICO}

Esta investigación recorre un amplio marco temporal, partimos de la Baja Edad Media marcada por diversas invasiones, una econo- mía autárquica, fanatismo religioso, grandes epidemias (Álvaro, 2001), las cruzadas y la guerra de los cien años. A nivel religioso, el cristianismo tiene una gran influencia y "se contemplan la pobreza, la humildad y la caridad como virtudes necesarias para alcanzar la salvación del alma” (Ferrer, 2001). Esta filosofía es de la que se impregna la asistencia a los enfermos durante la Edad Media, el enfermo es el vehículo a través del cual poner en práctica la caridad cristiana, el camino para la salvación del alma de aquellos que se dedicaban a asistirlos (Monje, 2003). Esta asistencia se presta en los hospitales medievales, instituciones que eran auspiciadas por la Iglesia se caracterizaban por ser "pequeños centros de acogida de enfermos y necesitados, con escasas camas y recursos" (Ferrer, 2001). En ellos pres$\tan$ sus servicios grupos organizados que se formalizan como familias religiosas acogidas a una regla, con sus propios estatutos y con una clara organización jerárquica (García Oro, 2001). La asistencia que se presta se fundamenta en el empirismo y en el saber intuitivo (Parrilla, 1999).

Continuamos por el Renacimiento, período convulso de la historia en el que toda Europa sufrió grandes cambios sociales, políticos, religiosos e incluso geográficos, con el Descubrimiento de América, y en el que se llevaron a cabo grandes avances científicos, no en vano se ha definido como "...un tiempo en el que se realizaron progresos sorprendentes no solo en las artes y la escritura, sino también en la arquitectura y en las artes médicas" (Donahue, 1985). A nivel religioso, la Iglesia Católica sufre fuertes críticas por su gran enriquecimiento y se encuentra con varios movimientos reformistas, el más destacado la Reforma Protestante de Martin Lutero y en contrapartida crea el Santo Oficio. La decadencia de la Iglesia es un 
hecho desde el s. XV, y con ella todas sus instituciones, incluidos los hospitales (García Oro, 2001).

La necesidad de saber y descubrir ya no tenía freno, contamos con la aparición y el rápido desarrollo de las Universidades como fuentes de conocimiento, donde se llevaron a cabo grandes avances en Anatomía, Fisiología, Circulación Sanguínea y Cirugía, "poco a poco se va imponiendo el método experimental a pesar de las intervenciones de la Santa Inquisición" (Aliete, 2003). Todo esto hace que las virtudes de pobreza y caridad vayan perdiendo valor y ganándolo la creencia de llegar a la virtud y a la salvación del alma a través del trabajo (Monje, 1998), "Se intenta pasar de una sociedad en la que es virtuoso sufrir por las llagas, la enfermedad y la pobreza, a otra en la que se va adquiriendo cierto status gracias a la capacidad para trabajar y generar riqueza" (Monje, 2003). Esto deriva en esa decadencia de las instituciones religiosas y en que los Estados pretendan controlar ellos mismos la asistencia social y pretendan desvincular a los religiosos de estas tareas (Monje, 1998).

En este marco histórico se mueve nuestro trabajo, de hecho la mayoría de este contexto histórico es palpable en el pequeño submundo que es el Hôtel-Dieu.

\section{DESARROLLO}

\section{Reformas físicas}

Los diferentes autores consultados, (Coyecque, 1891; Chevalier, 1901; Valentin, 1977; Aparcio, 1979...) atribuyen el inicio de las reformas del Hôtel-Dieu a Mauricio de Sully, el cual tras, ser nombrado Obispo de París en 1160 , comenzó a proyectar la reforma de todos los edificios metropolitanos de su sede; la Catedral, el Palacio Episcopal, el Claustro y el Hôtel-Dieu. Tres son los motivos reseñados para iniciar tales reformas; en primer lugar, la insuficiencia de los edificios para las necesidades reales de los mismos; en segundo lugar, las infraestructuras estaban anticuadas en cuanto a los servicios que presentaban; y por último, el estilo arquitectónico de la época los identificaba como "demodé" (Coyecque, 1891), no en vano debemos tener en cuenta que "... la forma de construcción de los hospitales responde sin duda a un criterio estético que se identifica con modas y tendencias que no responden a cuestiones prácticas" (Siles, 2011).

El nuevo Hôtel-Dieu se ubicó, según los documentos e imágenes encontradas, en la Île de la Citè, en la margen izquierda del Sena (Imagen 1), quedando entre el pequeño brazo del rio, la nueva Catedral y el Palacio Episcopal. Las obras de construcción del nuevo Hôtel-Dieu de París comienzan según los diferentes autores (Chevalier, 190; Coyecque, 1891; Cheymol, 1977...) en 1165. El hospital se construyó siguiendo el modelo de pabellones consecutivos, imperante en la época y contó en principio con cuatro salas, "Durante los siglos XII y XIII los mejores hospitales los podemos encontrar en Francia... el mayor y más famoso, será el Hôtel Dieu de Paris compuesto por cuatro grandes salas de dos naves" (Castro, 2012), aunque fue remodelado, reformado y ampliado en multitud de ocasiones entre los s. XII y XVIII, contando al final con once salas. A continuación vamos a detallar las diferentes salas con los datos que de ellas hemos encontrado (Imagen 2):

- 1195 - Sala de San Denis, el benefactor de esta sala fue el rey Felipe II, tenia $12 \mathrm{~m}$. de ancho y 10 de largo y se dedicó a la atención de hombres enfermos poco graves (Chevalier, 1901).

- 1210 - Sala de Santo Tomás, la benefactora de esta sala fue Blanca de Castilla, hija del rey Alfonso VIII de Castilla y reina consorte de Luis VIII de Francia (Coyecque, 1891). Esta 
sala era perpendicular a la anterior, se extendía $12 \mathrm{~m}$. y en ella se atendía a los convalecientes (Chevalier, 1901) así como a peregrinos y necesitados en general (Pietra Santa, 1866).

- 1225-1250 - Sala de la Enfermería, el benefactor fue el rey Luis IX, se construyó a continuación de Saint Denis, estaba dividida longitudinalmente en dos naves, se dedicó a los hombres enfermos más graves (Pietra Santa, 1866).

- 1250-1260 - Sala Nueva, era consecutiva a la Sala de la Enfermería, median entre ambas $122 \mathrm{~m}$. de largo y $24 \mathrm{~m}$. de ancho. Tuvo el mismo benefactor, también estaba dividida en dos naves y atendía a las mujeres (Chevalier, 1901).

- 1250-1260 - "Salle des Couches", que podríamos traducir por sala de maternidad, se encontraba en los sótanos bajo la Sala Nueva (Chevalier, 1901).

En 1260, con toda probabilidad, el nuevo Hôtel-Dieu de París estaba terminado y se llevó a cabo el traslado desde el antiguo, que había estado funcionando hasta este momento (Chevalier, 1901).

En los siglos posteriores, hasta el XVIII, se llevaron a cabo un gran número de reformas y ampliaciones, vamos señalar a continuación las más significativas:

- 1531 - Sala de Santa Marta, (Gazette Medicale, 1838), esta nueva reforma fue obra del Cardenal Antoine Duprat, que fue el primer Presidente del Parlamento Francés y Legado Papal, por esto la sala era más conocida como Sala del Legado. Se destinó a los afectados por la peste, se encontraba entre los edificios conventuales y las salas Nueva y de la Enfermería y contaba con 100 camas (De Pietra Santa, 1866).

- 1634 - Sala del Rosario, (Cheymol, 1977), según las Patentes Reales, Francisco I en 1515, ordenó "ampliar la construcción sobre el peque- no brazo del Sena, haciendo dos o tres pilares de piedra, con dos vigas en cada extremo para sujetar los arcos, y sobre ellos construir una gran sala de 5 o $6 \mathrm{~m}$. de ancho y 25 de largo" (De Pietra Santa, 1866). Esta nueva reforma no se inició hasta un siglo más tarde. El puente, que se terminó en 1632 (Cheymol, 1977), era conocido popularmente como Puente Doble, aunque en los planos del siglo XVII y XVIII aparece como Puente del Hôtel-Dieu. Dos años más tarde se termina también la sala elevada sobre el puente, que se usó como sala de maternidad.

- 1651 - Sala de San Carlos, elevan una nueva sala en esa ribera izquierda de Sena, se extendía de este a oeste y media $200 \mathrm{~m}$. de largo (Gazette Medicale, 1838). Quedó unida el mismo año a los edificios antiguos, los situados en la Île, por un puente privado, llamado Puente de San Carlos, cubierto posteriormente con una galería de vidrio que permitía el paso de las personas de un lado al otro del hospital sin exponerse al exterior (Cheymol, 1977).

- 1652 - Sala de San Cosme, la Sala de San Denis sufrió reformas que la ampliaron, dando lugar a dos salas; la Sala de San Denis y la Sala de San Cosme. Ésta última, debido al uso que se le dio era más conocida como Sala de los Soldados, ya que allí eran atendidos los heridos y mutilados de guerra.

- 1717 - Sala de Santiago y Sala de San Antonio, se realizaron alargando la Sala de San Carlos hasta el Petit Chatelete, pequeña fortificación que protegía el Petit-Pont y que posteriormente se convirtió en prisión (Cheymol, 1977).

Todas estas obras, reformas y ampliaciones nos hacen preguntarnos cual sería el número de personas que podía llegar a alojar el HôtelDieu pero, lamentablemente, no podemos dar respuesta a esta cuestión, la información encontrada nos ofrece cifras muy variadas, po- 
demos citar a Boudon, (1903) que nos habla de 630 pacientes en el s. XV; Chevalier (1901) los cifra en 500 a finales del mismo siglo; Pietra Santa (1866) marca en 2800 los enfermos alojados, tan solo en la parte de vieja del HôtelDieu (los edificios situados en la Île) en el s. XVII; Valentín (1977), aporta la cifra de 1200 camas en la parte nueva (los edificios situados en la orilla izquierda del rio); Castro Molina (2012) nos dice que en el s. XVII había alojamiento para 1280 pacientes en todo el recinto...Como decíamos, nos resulta imposible dar una cifra aproximada por no hallar un mínimo consenso entre los diferentes autores.

La noche del 30 de diciembre de 1772, un virulento incendio afectó gravemente todas estas instalaciones, dejando numerosísimas víctimas y grandes pérdidas materiales a su paso, haciendo imprescindible comenzar un nuevo proyecto de reformas del Hôtel-Dieu (Cheymol, 1977).

\section{Reformas estructurales}

El hospital estuvo funcionando con una jerarquía (Figura 1) completamente religiosa desde sus orígenes, también contaba desde 1217 con "Un severo reglamento que mantuvo el buen orden durante mucho tiempo, pero poco a poco los hermanos y hermanas infringieron las reglas y comenzaron a notarse sus negligencias..." (Filibien, 1725). Con el transcurrir del tiempo se fueron relajando las formas y esto se tradujo en diversos problemas, como son:

- Destitución del Prior en el s. XIII, por una acusación de desvío de capital (Chevalier, 1901).

- En el s. XIV una hermana es acusada y, tras ser hallada culpable, condenada a 14 años de confinamiento por infanticidio, ocurrido dentro de los muros del Hôtel-Dieu (Coyecque, 1891).

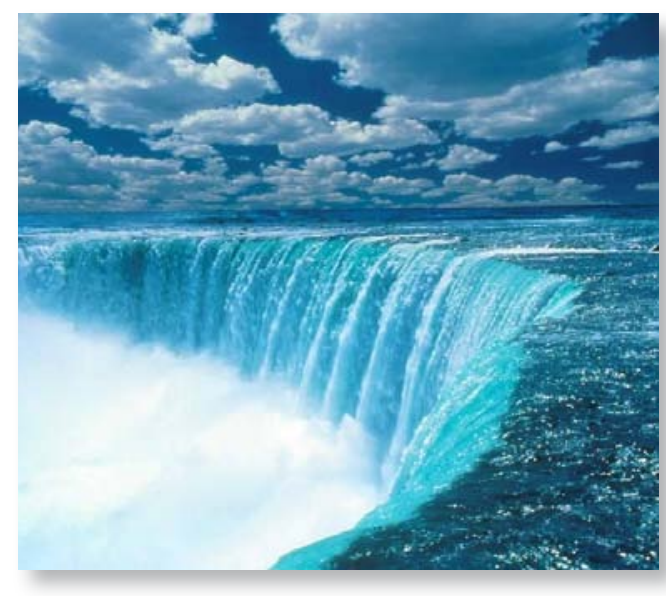

- En el mismo siglo la Priora y las hermanas se sublevan contra el Prior por un conflicto sobre las limitaciones de cada uno/a de ellos/as con el personal a cargo del otro/a (Chevalier, 1901).

- En 1482 se realiza un gran Capítulo General con todos/as los/as religiosos/as, desde el Obispo hasta la más nueva de las Filles Blanche, en el que los canónigos exigen un cambio de conducta y un mayor rigor profesional y religioso (Coyecque, 1891).

- En 1497 de nuevo es destituido el Prior, el personal religioso y laico del hospital se alza contra el Capítulo, llegando a atacar físicamente al Prior designado para sustituirlo, que de hecho falleció días más tarde (Aparicio, 1979). El Prior destituido es readmitido en el puesto pero, un año más tarde, es destituido de nuevo por la desaparición de un millar de libras de las cuentas del hospital (Coyecque, 1891).

Los enfermos fueron testigos de todas estas irregularidades, por lo que la opinión pública comienza a alzarse contra la administración de la institución, hasta poco tiempo antes, más querida por los ciudadanos de París. Todo esto conduce a la creación de una Comisión Parlamentaria para el estudio y la propuesta de mejoras en la administración del Hôtel-Dieu, cuya conclusión llega en 1505 (Lebeuf, 1754) 
como una Sentencia del Parlamento por la que se retira toda capacidad de gobierno a los Provisores y se sustituyen por una Junta de Gobierno (Figura 2), compuesta originariamente por "ocho simples burgueses de París" (Briele, 1870). Según esta sentencia, el Preboste y los Concejales de la villa eran los encargados de nombrar a los burgueses designados para administrar el Hôtel-Dieu, si el Parlamento los aceptaba como tal, "debían ser los Receptores y Procuradores de las ganancias del Hôtel-Dieu, de lo que rendirían cuentas todos los años en presencia del Presidente y de dos Consejeros del Parlamento..." (Filibien, 1725). Según el reglamento que establece la sentencia, esta Junta de Gobierno Municipal era elegida cada dos años, así como el Presidente y el Secretario de la misma. Con el transcurrir del tiempo, esos "simples burgueses", fueron sustituidos por personas socialmente relevantes; nobles, clérigos, eruditos, médicos... Para dar carácter oficial a este hecho, convertido en tradición, se dicta en 1690 una Patente Real que establece cuales serían los cargos municipales que van a llevar a cabo esta labor: "el Arzobispo de Paris, el Presidente del Parlamento, el Presidente de la Cámara de Cuentas, el Presidente de los Consejeros de la Corte, el Teniente de la Policía y el Presidente de los Comerciantes" (Briele, 1870)

Este cambio en la administración del Hôtel-Dieu no trajo la paz, las denuncias por desaparición de capital, por negligencias hacia los enfermos o por abusos de poder se siguieron sucediendo. Como ejemplo de esto podemos comentar que, para evitar la congestión del hospital, se decidió durante la segunda mitad del s. XVII, edificar un nuevo hospital para convalecientes, recibieron donativos de tres benefactores diferentes alcanzando una suma total de 130.000 libras pero nunca se edificó ni se justificó el uso de ese dinero (Gannal, 1892). Además, tenemos que sumar a estos problemas, los ocasionados por las disputas entre el gobierno laico y los Hermanos y Hermanas Agustinas, quienes ya sin capacidad de acción sobre la distribución de las ganancias, los donativos, las compras, los gastos diarios... quedan relegados ellos a las labores religiosas y ellas a las asistenciales.

En lo relativo a la asistencia prestada en el Hôtel-Dieu, este cambio en el sistema de administración, también trajo cambios hacia los enfermos. El hospital estaba permanentemente congestionado por el número de enfermos, a pesar de las múltiples ampliaciones, pero teniendo en cuenta descripciones como:

- "En el Hôtel-Dieu son recibidos, alimentados y atendidos todos los pobres enfermos, sin importar su país de procedencia ni la enfermedad que les haya traído, incluida la peste..." (Coyecque, 1888)

- "En el Hôtel-Dieu no solo se recibían a enfermos y enfermizos, también admitían a pobres, inválidos, indigentes, personas sin hogar $y$ carentes de recursos, peregrinos, viajeros..." (Chevalier, 1901)

- "Allí eran recibidos: viajeros y peregrinos; hambrientos, en los sucesivos periodos de hambruna; débiles, incapaces para el trabajo, mutilados de guerra; mujeres embarazadas, huérfanos; mendigos y vagabundos, muchas veces malandrines y taimados y así a todos los enfermos de cuerpo y espíritu" (Cheymol, 1977)

Podemos entender que uno de los primeros objetivos que se plantean estos administradores laicos es la descongestión del hospital, para lo cual establecen los siguientes criterios de derivación de enfermos:

- Peregrinos y viajeros - deberían acudir a hospedajes o alojamientos privados. 
- Pobres, mendigos y vagabundos - en 1656, por la presión de la Junta de Gobierno del Hôtel-Dieu, Luis XIV ordenó el confinamiento de los pobres en dos asilos, Biecêtre para los hombres y Salpêtriere para las mujeres.

- Huérfanos - fueron dirigidos a dos orfanatos Enfants Bleus y Enfants Rouge, creados en la segunda mitad del siglo XVI.

- Convalecientes - fueron derivados primero a la Sanidad de Saint Marcel y posteriormente también a la Sanidad de Sainte Ana.

- Ciegos - fueron derivados a la Casa de Salud Quinze-Vingts.

- Incurables - se enviaban al Hospital de los Incurables, fundado en 1634.

- Enfermos Mentales - los potencialmente "curables" eran atendidos en el Hôtel-Dieu, pero aquellos considerados incurables eran enviados a los asilos de pobres.

- Enfermos de peste, sífilis y otras enfermedades contagiosas - derivados al Hospital de San Luis, cuya construcción se inició en 1607 por deseo de Enrique IV (Castro, 2012).

En este sentido, el último gran cambio que encontramos es que "... a partir del siglo XVIII, el Hôtel-Dieu no aceptará más que a parisinos enfermos o lesionados" (Cheymol, 1977).

\section{Reformas funcionales}

La reforma del sistema de administración del hospital también se tradujo en cambios en la estructura jerárquica y funcional de la Orden de Hermanos y Hermanas Agustinas.

LOS HERMANOS - hasta el s. XVI la jerarquía no había variado, el Prior o "Magister" era la máxima autoridad y para facilitar la gestión de un establecimiento de tal importancia eran necesarios los “Officer” (Jehanno, 1986), "Para

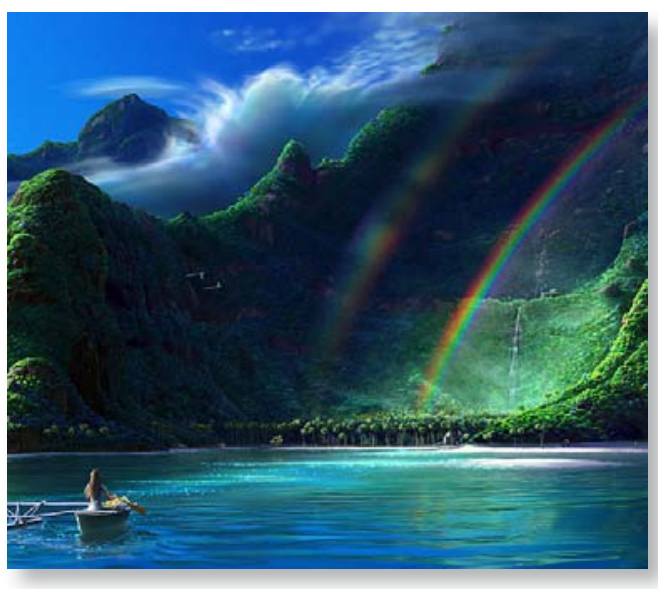

llevar a cabo todas sus competencias divide las mismas en siete departamentos funcionales, cada uno de ellos con un "Officer" que luego rendiría cuentas al Magister, éstos son; Maisonnerie - es decir, los dominios parisinos del hospital; Capilla; Bodega; Cocina y carnicería; Despensas; Sala del “Tesoro” y Pouillerie - en una traducción libre sería la "piojosería" (Teresa, 2013). Con los administradores laicos ya gestionando el hospital, los hermanos pierden dos de estos departamentos, la Maisonnerie y la Sala del Tesoro, ya que las cuentas, donativos y ganancias van a ser gestionados por la junta laica. Los problemas entre éstos y el Prior son tantos y tan continuos que, en abril de 1540, el Parlamento decide que, desde esa fecha, el Prior del Hôtel-Dieu, será elegido de entre los religiosos de la Abadía de San Víctor y no entre los agustinos, ya que estaban viciadas las relaciones entre los hermanos y los administradores. Tres meses más tarde, en sentencia parlamentaria, se confirma este punto $y$, además, la gestión de los Officer de la bodega, las despensas y la cocina pasa a ser laica (Coyecque, 1891). En 1580, les retiran la gestión de la "Piojosería", otorgándola a la Priora, quien le cambió el nombre por "Despouillerie”, que vendría a ser la "Despiojosería" (Boudon, 1903). Si bien en ningún momento de la histo- 
ria habían sido numerosos, en el s. XIII eran entre diez o doce hermanos (Chevalier, 1901) y en el s. XVI eran diez (Boudon, 1903), esta pérdida de autoridad y de competencias les lleva a su fin, desapareciendo completamente en 1661 la congregación masculina del hospital (Aparicio, 1979).

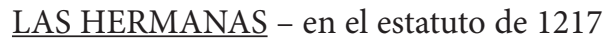
se establece la figura de la "Magistrae", que con el tiempo derivó en Priora, como máxima autoridad entre las hermanas y se marca en veinticinco el número máximo de éstas (Dubois, 1710), divididas en tres categorías; las hermanas profesas, las hermanas en el año de aprobación y las filles blanche (Teresa, 2013). Tres siglos más tarde, en 1580, se establece que "En el Hôtel-Dieu habrá cuarenta religiosas y 25 filles blanche, una será la Señora Priora, otra la Señora Supriora otra la Señora de la Botica, otra la Señora de la "Despiojosería”, otra la Señora de la Gran Lavandería y otra la Señora de la Pequeña Lavandería” (Boudon, 1903). Las atribuciones de la Priora eran de carácter económico, administrativo, punitivo, religioso y de supervisión de la asistencia "La priora, durante la noche hacia varias rondas, daba la instrucciones pertinentes y se retiraba, antorcha en mano" (Chevalier, 1901).

La Supriora cuyo cargo era llamado "Tronchere", se ocupaba de las cuentas tanto de la comunidad religiosa como del hospital y del buen funcionamiento general de la casa (Aparicio, 1979).

La Señora de la Botica, debemos decir que durante toda la Edad Media no hubo en el Hôtel-Dieu botica, el Prior compraba los preparados a los físicos de la ciudad (Chevalier, 1901). Fue en 1495 cuando se instauró este servicio, estaba compuesto por una hermana profesa, una fille blanche y un criado que pre- paraban y repartían las pócimas, ungüentos, emplastes... por las diferentes salas (Aparicio, 1979)

La "Despiojosería” era atendida por dos hermanas y una criada, se encargaban de recoger las pertenencias de los enfermos a su llegada, custodiaban sus bienes, tales como dinero y joyas, lavaban y reparaban sus ropas para devolvérselas al alta o para venderlas si fallecían y cada tres semanas iban al mercado con lo acumulado hasta entonces. Otro deber de estas hermanas era controlar la ocupación de las camas, para lo que llevaban un registro diario en el que se anotaba el nombre y el lugar de procedencia del enfermo y se le asignaba un número que se correspondía con el lugar que ocupaba, cama y sala (Chevalier, 1901).

La Gran Lavandería era un significativo evento que se daba una vez por semana, en el se lavaban todas las ropas de las camas del hospital y para llevarlo a cabo se contrataba a jóvenes de la ciudad ya que con las hermanas y las criadas disponibles no era suficiente (Coyecque, 1891). La Pequeña Lavandería era diaria, en ella se lavaban las ropas de los nuevos enfermos, se reparaban y blanqueaban las sabanas, almohadones y otras prendas estropeadas (Coyecque, 1891).

Encontramos tres cargos más entre las hermanas:

- Hermana Portera, encargada de recibir a los enfermos a su llegada, inscribirlos en el registro de entrada y asignarlos a una u otra sala en función de las características de la dolencia que les hubiera llevado allí.

- Hermana "Cheftaine" (Chevalier, 1901) o "Chevetaine" (Coyecque, 1891), eran las encargadas de cada sala, llevaban la coordinación entre ésta y la botica, la cocina y la pequeña lavandería, para que la sala no se quedara de- 
sabastecida de ropa y los enfermos recibieran las medicinas y alimentos prescritos. También asignaban a cada hermana y fille blanche que trabajaban en su sala los enfermos que iban a estar a su cargo (Coyecque, 1891).

- Hermana Partera, los partos eran atendidos por una Partera, externa al hospital y que siempre era acompañada por la misma hermana, la Hermana Partera (Chevalier, 1901).

Cuando una fille blanche ingresaba en la orden, era asignada a una hermana y a la misma sala en la que ésta ejercía sus labores, desde entonces ya no cambiaría de sala hasta que sus condiciones físicas, la edad o la muerte la retiraran del servicio. El único cambio que se producía era el cambio de turno; tenían un año de turno diario, desde las $6 \mathrm{~h}$. a las $19 \mathrm{~h}$. y un año de turno nocturno, el resto del día, las hermanas y fille blanche del turno nocturno eran llamadas Veladoras. Descansaban cinco días al año, el día de la Ascensión, Pentecostés, Corpus Cristi, San Juan Bautista (patrón del HôtelDieu) y Asunción (Chevalier, 1901).

Según algunos autores, a lo largo de la Edad Media y los principios de la Edad Moderna, el número total de hermanas fue aumentando progresivamente, desde las cuarenta reseñadas anteriormente a doscientas (Aparicio, 1979) y posteriormente a cuatrocientas (Chevalier, 1901).

\section{MÉDICOS Y CIRUJANOS - desde sus} orígenes hasta el s. XIII, en el Hôtel-Dieu los enfermos fueron atendidos por aquellos canónigos y hermanos con estudios en medicina. Fue en 1221 la primera vez que el Prior llegó a un convenio con un médico y un cirujano, llamado Maitre Hubert (Mackay, 1923), para que éstos atendieran a los enfermos y al personal del hospital de forma gratuita, aunque en agradecimiento se les estableció, en 1234, una asignación de cuatro libras anuales (Mackay, 1923). Existen indicios que hacen creer que ya en el s. XIV el hospital era un centro dedicado a la enseñanza de la práctica médica debido a la proximidad de la Universidad de Medicina que se encontraba detrás de la Sala de San Carlos, en la Rue Rats, y a que, según el Reglamento de los Cirujanos de París, éstos recibían "sus ropas y sus artes" de "Maitre Chirurgien" del Capítulo de Notre Dame. En 1328, en una Patente Real, Carlos IV obliga a que sean dos los cirujanos que trabajen en el Hôtel-Dieu, cobrando doce peniques por día, que serían sufragados por los impuestos abonados por los ciudadanos de París (Chevalier, 1901). Los pagos a los médicos y cirujanos comienzan a aparecer en los libros de cuentas ya a finales del s. XV (Briele, 1870). Según los documentos encontrados, los cirujanos, barberos y maestros sangradores acudían cuando eran solicitados, bien para intervenir a los enfermos, hacer sangrías, curar las heridas quirúrgicas... Los médicos, en cambio, acudían dos veces al día, por la mañana y por la tarde, llevaban a cabo un pase de sala, visitando a diario a todos los enfermos y prescribiendo medicinas purgativas y sanadoras, dietas, baños, electuarios, emplastes y pócimas (Chevalier, 1901).

\section{CONCLUSIONES}

En relación a las grandes y múltiples obras del Hôtel-Dieu, podemos entenderlas, contextualizándolas. Estamos en un periodo de tiempo en el que demostrar era más importante que ser; demostrar la nobleza, la riqueza, la religiosidad, la caridad... por lo que es bastante lógico que uno de los motivos para llevarlas a cabo fuera que los edificios no se ajustaban al patrón arquitectónico del momento o la cantidad de donativos que percibían para di- 
chas obras, así como que las salas tuvieran benefactores conocidos y que se incluyeran sus escudos de armas o emblemas familiares en las ornamentaciones.

Sobre las diferencias encontradas en el número de pacientes para los que tenía capacidad, creemos que estas diferencias entre autores pueden deberse a que la sobre-ocupación y el uso compartido de las camas eran prácticas habituales en la Edad Media, esto permite que ocurran cosas como que la Sala del Legado, una de las más pequeñas, tenga 100 camas y 200 pacientes. Podemos concluir que el número de enfermos podía ser extremadamente elevado, así como el nivel de hacinamiento de los mismos.

El siguiente punto de interés son los cambios en la administración, nos sorprende que, al menos al principio, los cambios fueran tan sólo a nivel de gestión económica, ya que era evidente la problemática que esto iba a generar; laicos frente a religiosos, beneficencia y caridad frente a gestión económica, altruismo frente a resultados... Este cambio en la orientación de la política de la institución es un gran paso hacia la asistencia sanitaria profesional, es el paso intermedio entre la Casa de Dios, con cabida para todos y un hospital de la Edad Moderna con criterios de inclusión y exclusión. Este hecho lo vemos confirmado en la criba de pacientes que hacen desde el s. XVI, lo que hace también necesaria la coordinación entre el hospital y diferentes instituciones; socio-sanitarias como los asilos de pobres y germen de los primeros manicomios o como las casas de sanidad antecesoras de los hospitales para crónicos; puramente sanitarias como los hospitales para infecto-contagiosos y, por último, las instituciones exclusivamente sociales como los orfanatos. En estos cambios queda claramente manifiesta la modernización de la

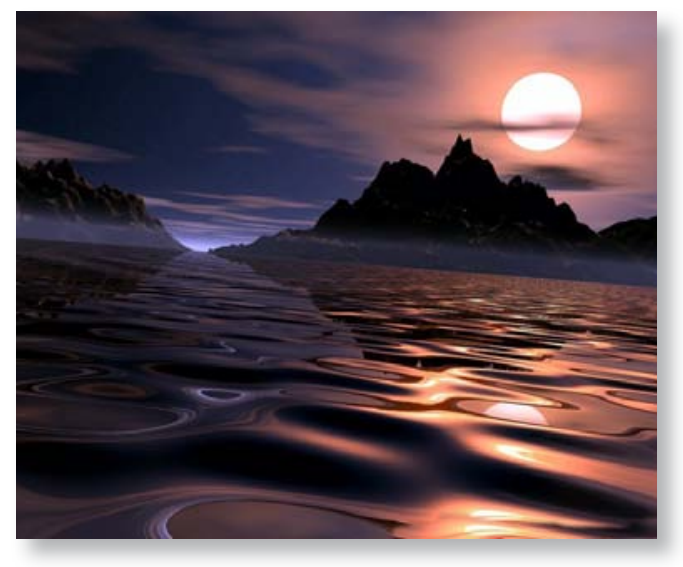

atención y la tendencia a la profesionalización de la misma. En tres siglos se observa una clara tendencia renovadora del sistema y en estos cambios vemos los orígenes del actual sistema sanitario francés.

En cuanto a las hermanas enfermeras y su jerarquía hospitalaria, encontramos un gran paralelismo con la actual organización en cualquier centro de asistencia especializada (ver Figura 3). Donde sí hallamos diferencias es en la relación entre los diferentes cargos intermedios y la dirección.

Otro punto que nos parece muy interesante es la figura de la Hermana Portera, la podríamos asemejar a una enfermera de clasificación de urgencias. El médico no iba a ver al paciente hasta el siguiente pase de sala, por lo que el peso de una primera aproximación al diagnóstico recaía sobre ella, lo que se traduce en una enorme responsabilidad y un gran nivel de confianza en sus capacidades como profesional sanitario para el desempeño de este puesto.

Mención especial debe tener lo que nosotros hemos venido a denominar "especialización de por vida" de las hermanas. Las hermanas podían pasar en torno a cincuenta años, que son muchos años, en la misma sala atendiendo al mismo tipo de enfermos por lo que es lógico pensar que serían unas excepcionales 
especialistas de dicha atención. Ni que decir tiene que la mortalidad más alta entre ellas se daba en la Sala del Legado, dedicada a enfermos de peste.

La Hermana Partera también nos resulta sorprendente, ¿cincuenta años asistiendo partos y era necesaria una partera externa? Hemos encontrado en documentos religiosos referencias a lo "sucio" del acto de partear, por lo que suponemos que, aun siendo perfectamente capaz de asistirlos sola, no sería adecuado que una mujer religiosa, sometida a voto de castidad, se enfrentara sola a este proceso. Si bien, con lo impredecible de los partos, suponemos que se verían obligadas a atenderlos, a solas, aunque fuera de un modo encubierto.

Sobre los turnos y los descansos, trabajar trece $\mathrm{u}$ once horas diarias, en función de si estaban en el año de turno diurno o de turno nocturno, nos rompe todos los esquemas, y si le sumamos los cinco descansos al año, debía ser completamente agotador, sólo se puede entender si nos recordamos que estamos hablando de la Edad Media.

Estas conclusiones nos hacen surgir nuevas inquietudes; cómo se formaban las hermanas, qué tipos de cuidados aplicaban, cómo fue la llegada de las Hermanas de la Caridad al centro, cómo actuaban ante las grandes epidemias o cómo se gestionaba el aspecto de hospital universitario son algunas de las inquietudes que más nos atraen para trabajos futuros.

\section{BIBLIOGRAFÍA}

- Aliete Pedrosa (2003) Os cuidados na doenca e os servicios asistenciais desde a Renasceca até à Revolucao Industrial. Rev. Referencia 10:81-90

- Álvaro Barra, M.P.; Morlans Loriente, M.J.; Peña Tejeiro, E.; Gómez Galán, R. y Garrido González, J. (2001) La estructura hospitalaria, los cuidados y cuidadores en los hospitales extremeños en la Baja Edad Media. Rev. Cultura de los Cuidados 5(9):22-26
- Aparicio López, T. (1979) Las Religiosas Agustinas del Hôtel-Dieu de Paris. Rev. Archivo Agustiniano 63 (181):81-108

-Boudon, G. (1903) Le Reglament de l'Hôtel-Dieu de Paris en 1580. Bulletin de la Societe de la Histoire de Paris et de l'Ile de France. (30)

- Briele, L. (1870) L'Histoire de L'Hôtel-Dieu de Paris, Ed. Ernest Thorin, Paris.

- Castro Molina, F.C.; Castro González, M.P.; Megías Lizanco, F.; Martín Casañas, F.V. y Causapie Castro, A. (2012) Arquitectura hospitalaria y cuidados durante los siglos XV al XIX”. Rev. Cultura de los Cuidados 16(32):38-46

- Chevalier, A. (1901) L'Hôtel-Dieu de Paris et le Soeurs Agustines. Libraire de la Societe de l'Histoire de Paris, Paris

- Cheymol, J. et Cesar, R.J. (1977) Hôtel-Dieu de Paris: treize siecles d'histoire... panegyrique ou requisitoire, Historie des Sciences Medicales, 11(4):263-283

- Coyecque, E. (1891). L'Hôtel-Dieu de Paris au Moyen Age, Ed. Daupeley-Gouverneur, Paris

- Coyecque, E. (1888) L'Assistance Publique a Paris Au Milieu Du XVI Siecle. Bulletin de la Societe de la Histoire de Paris et de l'Ile de France. (15)

- Donahue, M.P. (1985) Historia de la enfermería. Doyma, Madrid

- Dubois, G. (1710). Historia Ecelsiae Parisiensis (t2). Societatem Bibliopolarum Parisiensiu, Paris

- Eseverri Chaverri, C. (1996-1997). La Enfermería Medieval. Un documento histórico. Rev. Híades 3-4

- Felibien, M. (1725) Histoire de le ville de Paris. Ed. Desprez y Desessartz, Paris

- Ferrer Cano, F. (2001) El cuidado en la España Medieval. Una aproximación a la enfermería institucional. Rev. Index de Enfermeria, 10(34):48-51

- Gannal, F. (1892) Une Page de l'Histoire de l'Hôtel-Dieu (1660-1677). Bulletin de la Societe de la Histoire de Paris et de l'Ile de France. (19)

- García Oro, J.; Portela Silva, Ma J. (2001) La asistencia hospitalaria de las órdenes religiosas durante el Renacimiento. Rev. Initium, 6:715-784

- Gazette Medicale, (1838) Hôtel-Dieu de Paris- Sa Demolition. Gazette Medicale de Paris 6(34) 
- Jehanno, C. (1986) Boireà Paris au XV siécle: le vin à l'Hôtel-Dieu. Revue Historique (Paris) 559:3-28

- Lebeuf, J. (1754) Histoire de le ville et de tout le Diocesis de Paris (tomo 1), Ed. Prault, Paris.

- Mackay, M.L. (1923) Les hospitaux et la charite a Paris. Ed. Champion, Paris

- Monje Juárez, M. (1998) Miseria de la economía. La controversia sobre la asistencia social y hospitalaria en el siglo XVI. Rev. Cultura de los Cuidados 2 (3):30-40

- Monje Juárez, M. (2003) Los cuidados enfermeros como estrategia de cambio económico y social en el Renacimiento Europeo. Rev. Index de Enfermería, 12(43):55-58

- Nutting, M.A. y Docks, L.L. (1907) A history or nursing. The evolution of nursing systems from of the earliest time to the foundation of the first English and American training school of nursing. (vol. 2) G.P. Putnam's Sons, New York

- Parrilla Saldaña, J. y Sanchez Nario, A. (1999) Los hospitales de Sevilla en la Baja Edad Media. Rev. Híades 5-6:103-114

- Pietra Santa, de P. (1866) L'Hôtel Dieu de Paris: Son Passé- Son Avenir. Rev. L'Union Medicale 32.

- Siles González, J. (2011) Historia de la Enfermería. Ed. DAE, Madrid.

- Teresa Morales, C. y García Berrocal, F.J. (2013) HôtelDieu de Paris: orígenes y aparición de las primeras enfermeras religiosas de la historia. Rev. Cultura de los Cuidados, 17(35):42-54

- Valentin, M. (1977) Quelques documents sur L'HôtelDieu, Histoire des Sciences Medicales 11(4):251-262

IMAGEN 1 - "PLAN DE PARIS" DE LA COLECCIÓN “DOCUMENTS OF FRENCH ARCHITECTURE AND TOPOGRAPHY" DE KYOTO UNIVERSITY LIBRARY DIGITAL DISPONIBLE EN http://edb.kulib.kyoto-u.ac.jp

LEYENDA

A - ÎLE DE LA CITÈ

B - PEQUEÑO BRAZO DEL SENA

C - HÔTEL-DIEU

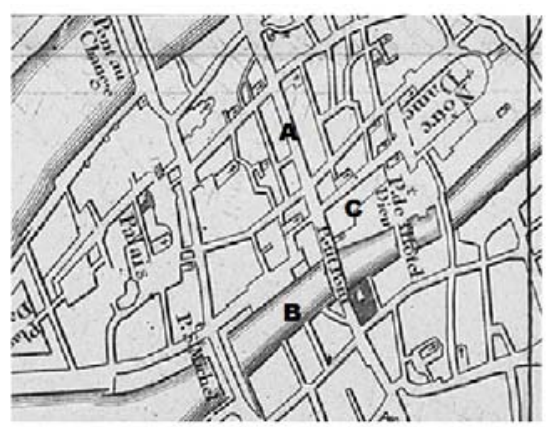

IMAGEN 2 - PLAN DE TURGOT (1734)

DISPONIBLE EN http://plan.turgot.free.fr

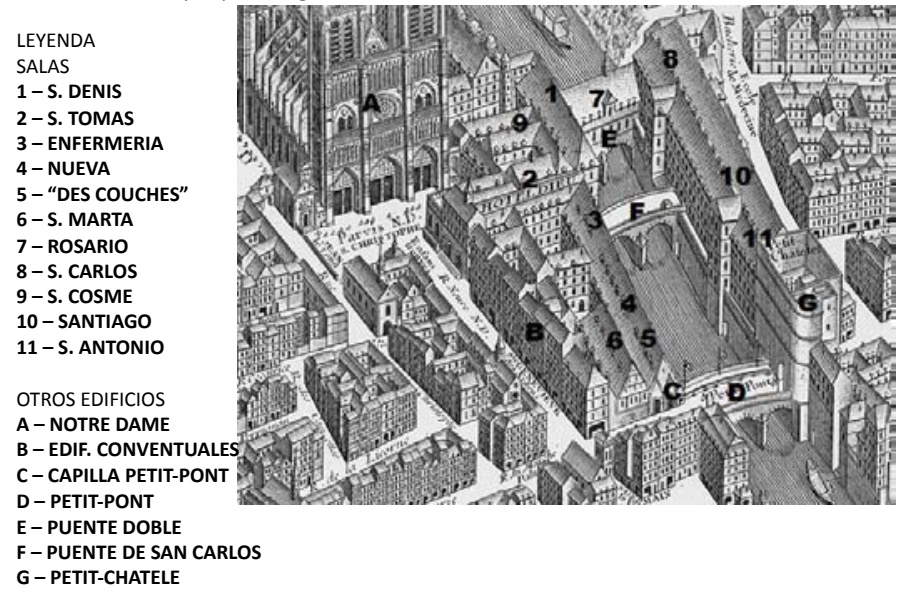




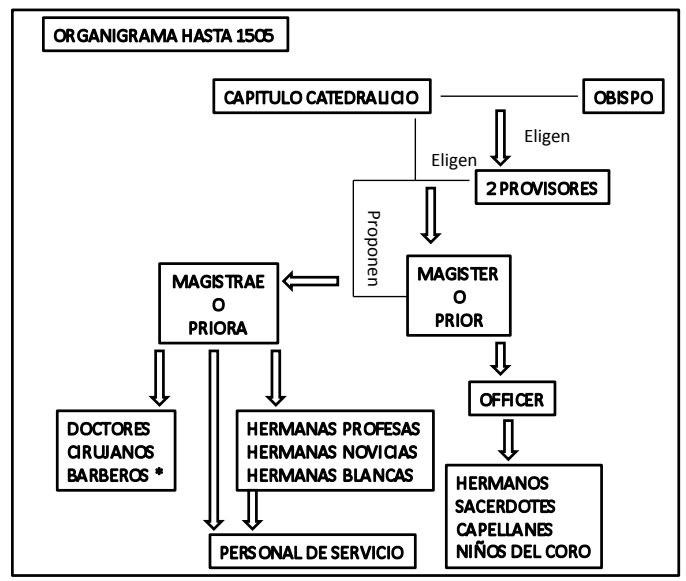

FIGURA 1

ORGANIGRAMA

DEL HÔTEL-DIEU

HASTA 1505

*ESTE GRUPO

PROFESIONAL

APARECE EN

EL S. XIII

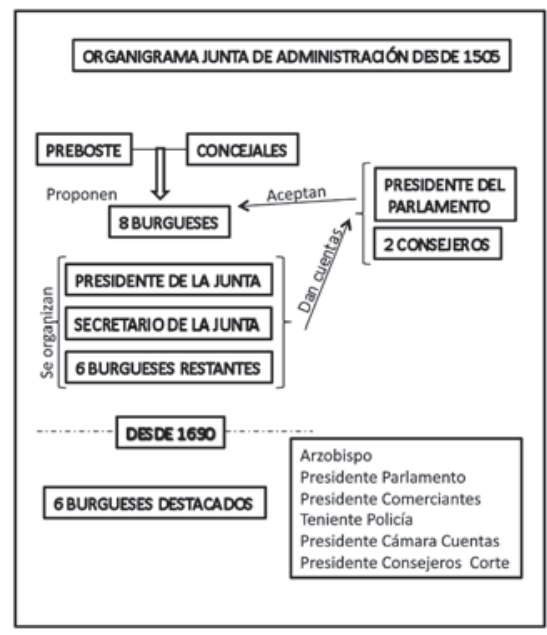

FIGURA 2-

ORGANIGRAMA

DE LA JUNTA

DE GOBIERNO

DEL HÔTEL-DIEU

DESDE 1505

FIGURA 3 - PARALELISMO ENTRE LA ESTRUCTURA ORGANICA DEL HÔTEL-DIEU DESDE EL S. XVI Y LA ACTUAL EN LOS CENTROS DE ASISTENCIA HOSPITALARIA

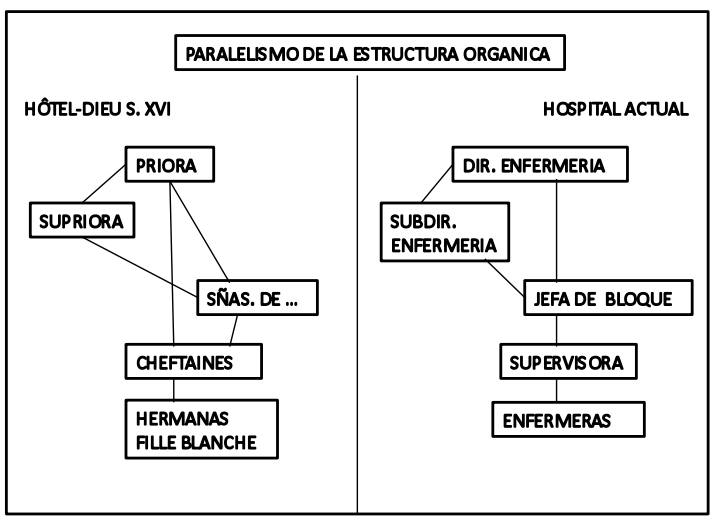

